\title{
Correlation of serum intact parathyroid hormone and alkaline phosphatase in diabetic chronic kidney disease stage 3 to 5 patients with mineral bone disorders
}

\author{
Mehruba Alam Ananna, Wasim Md. Mohosin Ul Haque, Muhammad Abdur Rahim, \\ Tufayel Ahmed Chowdhury, Tabassum Samad, Md. Mostarshid Billah, Sarwar Iqbal \\ Department of Nephrology, Ibrahim Medical College and BIRDEM General Hospital, \\ 122 Kazi Nazrul Islam Avenue, Shahbag, Dhaka-1000, Bangladesh
}

\begin{abstract}
Introduction: Chronic kidney disease (CKD) amongst diabetic patients is a worldwide public health problem. It is associated with cardiovascular disease and CKD mineral bone disorder (CKD-MBD). Cardiovascular and MBD are important contributors of morbidity and mortality in CKD patients. Serum intact parathyroid hormone (iPTH) and alkaline phosphatase (ALP) are two important markers to identify and mange CKD-MBD. This study was designed to evaluate the relationship between serum iPTH and alkaline phosphatase in diabetic CKD stages 3-5 patients with MBD.

Methods: This cross-sectional study was conducted in BIRDEM General Hospital, Dhaka, Bangladesh from January 2013 to December 2014. Diabetic patients suffering from stage 3-5 CKD with MBD and not on dialysis, were consecutively and purposively included in this study. Along with base-line characteristics, clinical and laboratory data including serum alkaline phosphatase and iPTH levels were recorded for all patients. Data were analyzed by using SPSS version 20.0 and Pearson's correlation test was applied to evaluate the relationship between iPTH and serum ALP.

Results: Total patients were 306, of which 166 (54.2\%) were males and 140 females (45.8\%). Mean age of the study population was $56.5 \pm 11.3$ years. Mean duration of diabetes mellitus (DM) and CKD were $12.8 \pm 7.6$ and $2.9 \pm 1.7$ years respectively. Among the study population, $49(16.0 \%)$ were in CKD stage 3, 90 (29.4\%) in stage 4 and rest $167(54.6 \%)$ in stage 5. The mean HbA1c level did not differ significantly ( $p>0.05$ by ANOVA) amongst CKD-MBD stage 3, 4 and 5 cases. Mean \pm SE values of glycated haemoglobin (HbAlc \%), serum creatinine $(\mathrm{mg} / \mathrm{dl})$, urea $(\mathrm{mg} / \mathrm{dl})$, calcium $(\mathrm{mg} / \mathrm{dl})$, phosphate $(\mathrm{mg} / \mathrm{dl})$, ALP (U/L) and iPTH $(\mathrm{pg} / \mathrm{ml})$ of total study population were $7.77 \pm 0.12,6.8 \pm 0.17,141.1 \pm 4.33,8.1 \pm 0.07$, $5.2 \pm 0.11,164.1 \pm 7.74$ and $229.7 \pm 8.64$ respectively. Out of total cases, serum ALP was raised in only $53.9 \%$ CKD-MBD cases compared to $76.8 \%$ for iPTH. Serum iPTH level was found elevated in $79.6 \%, 83.3 \%$ and $72.5 \%$ CKD-MBD stage 3, 4 and 5 cases respectively while in comparison, serum ALP was found raised in $44.8 \%, 54.4 \%$ and $56.2 \%$ cases respectively. On correlation analysis between serum iPTH and ALP, the $r$ values observed were $0.074,0.231$ and 0.046 for stage 3,4 and 5 CKD-MBD cases respectively.
\end{abstract}

Conclusion: The results of current study showed that most diabetic stage 3-5 pre-dialysis CKD-MBD patients had raised serum iPTH. In comparison, significantly low number of cases had raised serum ALP.

IMC J Med Sci 2018; 12(2): 80-85. EPub date: 31 December 2018

Address for Correspondence:

Dr. Mehruba Alam Ananna, Assistant Professor, Department of Nephrology, Ibrahim Medical College and BIRDEM General Hospital, 122 Kazi Nazrul Islam Avenue, Shahbag, Dhaka, Bangladesh. Email: ananna0701@gmail.com 


\section{Introduction}

Chronic kidney disease is a worldwide public health problem with increasing prevalence and potentially lethal adverse outcomes like progressive loss of renal function, cardiovascular disease and premature death. Ten percent of the population worldwide is affected with CKD and millions die each year because they do not have access to affordable treatment [1]. Among the different causes, diabetes mellitus (DM) is one of the leading causes of endstage renal disease (ESRD) worldwide, though glomerulonephritis has been the more predominant cause in developing countries [2]. As a part of different metabolic disturbances, CKD causes alterations in mineral homeostasis affecting serum calcium, phosphate, serum ALP and iPTH. As a result of these changes in the mineral homeostasis there is increased risk of bone, vascular disease and disorder of mineral metabolism. Vascular calcification and bone disease labeled as CKD mineral bone disorder (CKD-MBD) are of particular concern. These abnormalities related to mineral metabolism and bone disorders have been implicated as novel risk factors and associated with increased morbidity and mortality in patients with CKD [3]. Greater risk of hip fractures and associated increased mortality in patients with CKD and ESRD has been reported [4-7].

Serum iPTH and ALP are two important markers to identify and mange CKD-MBD. These two markers are useful to guide the medical management of CKD-MBD.

In human there are four isoenzyme forms of ALP, which are tissue non-specific, intestinal, placental and germ cell ALPs. Among these four types, tissue nonspecific isoenzyme is of particular interest in $\mathrm{CKD}$, as tissue non-specific ALP exists in numerous isoforms and primarily differ in extent and type of glycosylation [8]. Bone ALP is an ectoenzyme anchored to the membrane of osteoblasts and thus reflects overall bone remodeling [9].

Few studies have suggested serum ALP as a potential biomarker of CKD-MBD and may be superior compared to iPTH as it shows less inter and within individual biological variation [10]. On the other hand, iPTH has a very short half-life of 2-4 minutes compared to 1.5 to 2.3 days of bone ALP. Also, iPTH has significant inter individual biological variation especially in patients undergoing hemodialysis. In addition, there is an analytical variation amongst clinical laboratories and lack of standardization of second and third generation commercially available iPTH assays [11].

Higher ALP levels in CKD patient correlate with increased mortality and progression to ESRD as well as progressive peripheral arterial calcification. There are similar association between higher total ALP levels and increased mortality in maintenance hemodialysis and peritoneal dialysis patients [12]. Several studies have reported total ALP appeared to be a more consistent and better predictor of adverse outcomes than iPTH. In a cohort of 74,000 patients there was $U$ shaped correlation between mortality and iPTH level whereas ALP showed linear and incremental correlation [13]. Thus, ALP is a promising tool that has the potential to guide CKD-MBD management. But there are insufficient local data in this regard. So, the present study was undertaken to evaluate the serum ALP level in CKD stages 3-5 pre-dialysis patients with diabetes mellitus and to see its correlation with serum iPTH level in different stages of CKD patients.

\section{Methods}

This cross-sectional study was conducted in BIRDEM General Hospital, Dhaka, Bangladesh from January 2013 to December 2014. All diabetic patients suffering from CKD stage 3-5 with MBD were purposively included in this study. CKD-MBD was defined as a systemic disorder of mineral and bone metabolism due to CKD manifested by either one or a combination of the (a) abnormalities of calcium, phosphorus, iPTH or vitamin D metabolism (b) abnormalities of bone turnover, mineralization, volume, linear growth or strength (c) vascular or other soft tissue calcification [13]. CKD was diagnosed and staging done as per Kidney Disease: Improving Global Outcomes (KDIGO) Clinical Practice Guidelines 2012 [14]. eGFR was estimated by using chronic kidney disease-epidemiology (CKDEPI) creatinine based formula .

Patients who had history of parathyroid disorders/ surgery, primary or metastatic bone disease and diagnosed with any genetic or hereditary conditions were excluded from the study. Cases undergoing dialysis were also excluded. Base-line characteristics 
and laboratory data including serum ALP and iPTH levels of all enrolled patients were recorded. Serum iPTH was determined by Chemiluminescent Micropartical Immunometric Assay (CMIA). Data were analyzed by using SPSS version 20.0 and correlation test was applied to evaluate the relationship between ALP and iPTH. The normal range of serum ALP and iPTH were 45 to $115 \mathrm{U} / \mathrm{L}$ and $7-53 \mathrm{pg} / \mathrm{ml}$ respectively. Consent was obtained from enrolled participants.

\section{Results}

In the present study, there were 306 participants who satisfied the selection criteria and out of them 166 (54\%) were male. Mean age, duration of DM and duration of CKD of the study participants were $56.5 \pm 11.3,12.8 \pm 7.6$ and $2.9 \pm 1.7$ years respectively. Among the study population, 49 (16.0\%) were in CKD stage 3, 90 (29.4\%) in CKD stage 4 and rest 167 (54.6\%) were in CKD stage 5. Twothirds $(202,66 \%)$ of the study participants were receiving calcium and vitamin $\mathrm{D}, 52(17 \%)$ were receiving only calcium and equal number $(52,17 \%)$ were not on any treatment regarding CKD-MBD.
Base-line biochemical parameters of the total study participants are presented in Table 1.

Selected biochemical parameters of CKD-MBD cases in different stages of CKD are presented in Table-2. Mean HbAlc (\%) in CKD stages 3, 4 and 5 were $8.36 \pm 0.22,7.99 \pm 0.20$ and $7.77 \pm 0.17$ respectively. The difference amongst the stage 3,4 and 5 were not significant by ANOVA. Serum albumin was significantly ( $p<0.01$ by ANOVA) reduced in stage $5 \mathrm{CKD}-\mathrm{MBD}$ cases compared to stage 3 and 4 cases.

Table-1: Base line biochemical characteristics of the study population $(n=306)$

\begin{tabular}{lc}
\hline \multicolumn{1}{c}{$\begin{array}{c}\text { Biochemical } \\
\text { parameters }\end{array}$} & Value (Mean \pm SE) \\
\hline HbA1c & $7.77 \pm 0.12 \%$ \\
Urea & $141.1 \pm 4.33 \mathrm{mg} / \mathrm{dl}$ \\
Creatinine & $6.8 \pm 0.17 \mathrm{mg} / \mathrm{dl}$ \\
Calcium & $8.1 \pm 0.07 \mathrm{mg} / \mathrm{dl}$ \\
Phosphate & $5.2 \pm 0.11 \mathrm{mg} / \mathrm{dl}$ \\
Alkaline phosphatase & $164.1 \pm 7.74 \mathrm{U} / \mathrm{L}$ \\
iPTH & $229.7 \pm 8.64 \mathrm{pg} / \mathrm{ml}$ \\
\hline
\end{tabular}

Table-2: Biochemical parameters of stage 3-5CKD-MBD cases $(N=306)$

\begin{tabular}{cccccc}
\hline $\begin{array}{c}\text { CKD } \\
\text { stage }\end{array}$ & $\begin{array}{c}\text { Number of } \\
\text { case (\%) }\end{array}$ & $\begin{array}{c}\text { HbA1c (\%) } \\
\text { Mean } \pm \text { SE }\end{array}$ & $\begin{array}{c}\text { Ca (mg/dl) } \\
\text { Mean } \pm \text { SE }\end{array}$ & $\begin{array}{c}\text { PO4 (mg/dl) } \\
\text { Mean } \pm \text { SE }\end{array}$ & $\begin{array}{c}\text { Albumin (gm/dl) } \\
\text { Mean } \pm \text { SE }\end{array}$ \\
\hline 3 & $49(16.0)$ & $8.36 \pm 0.22$ & $9.11 \pm 0.11$ & $4.02 \pm 0.22$ & $36.75 \pm 1.54$ \\
4 & $90(29.4)$ & $7.99 \pm 0.20$ & $8.65 \pm 0.09$ & $4.09 \pm 0.13$ & $35.63 \pm 0.74$ \\
5 & $167(54.6)$ & $7.77 \pm 0.17$ & $8.06 \pm 0.09$ & $5.21 \pm 0.15$ & $31.43 \pm 0.50$ \\
\hline
\end{tabular}

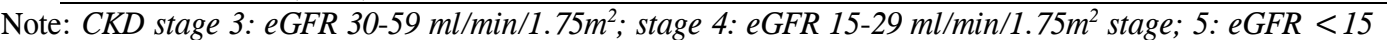
$\mathrm{ml} / \mathrm{min} / 1.75 \mathrm{~m}^{2}$.

Table-3: Comparative rate of raised serum $i P T H$ and ALP levels in stage 3, 4 and 5 CKD-MBD cases

\begin{tabular}{lcccccc}
\hline \multirow{2}{*}{$\begin{array}{c}\text { CKD } \\
\text { Stage }\end{array}$} & \multirow{2}{*}{$\begin{array}{c}\text { No of } \\
\text { case }\end{array}$} & \multicolumn{2}{c}{ Raised serum iPTH (pg/ml) } & \multicolumn{2}{c}{$\begin{array}{c}\text { Raised serum Alkaline } \\
\text { phosphatase (U/L) }\end{array}$} & \multirow{2}{*}{ p value } \\
\cline { 3 - 6 } & & $\mathbf{N}(\%)$ & Mean \pm SE & N (\%) & Mean \pm SE & \\
\hline Stage 3 & 49 & $39(79.6)$ & $262.74 \pm 32.46$ & $22(44.8)$ & $166.5 \pm 8.99$ & \\
Stage 4 & 90 & $75(83.3)$ & $197.61 \pm 22.5$ & $49(54.4)$ & $193.07 \pm 16.01$ & \\
Stage 5 & 167 & $121(72.5)$ & $294.18 \pm 6.95$ & $94(56.2)$ & $233.65 \pm 16.86$ & $<0.01^{*}$ \\
Total & 306 & $235(76.8)$ & - & $165(53.9)$ & - & \\
\hline
\end{tabular}

Note: $p>0.05$ when the rate of occurrence of raised serum $i P T H$ or ALP in CKD stage 3, 4 and 5 cases are compared with each other by $Z$ test. $p>0.05$ when mean serum ALP values was compared amongst the 3 groups by ANOVA. For $i P T H: 2$ vs $3 p=0.035 ; 1 v s 2$ and $1 v s 3 p=0.43$ and 0.79 respectively by ANOVA. *Compared the rate of occurrence of raised serum $i P T H$ with that of ALP. 


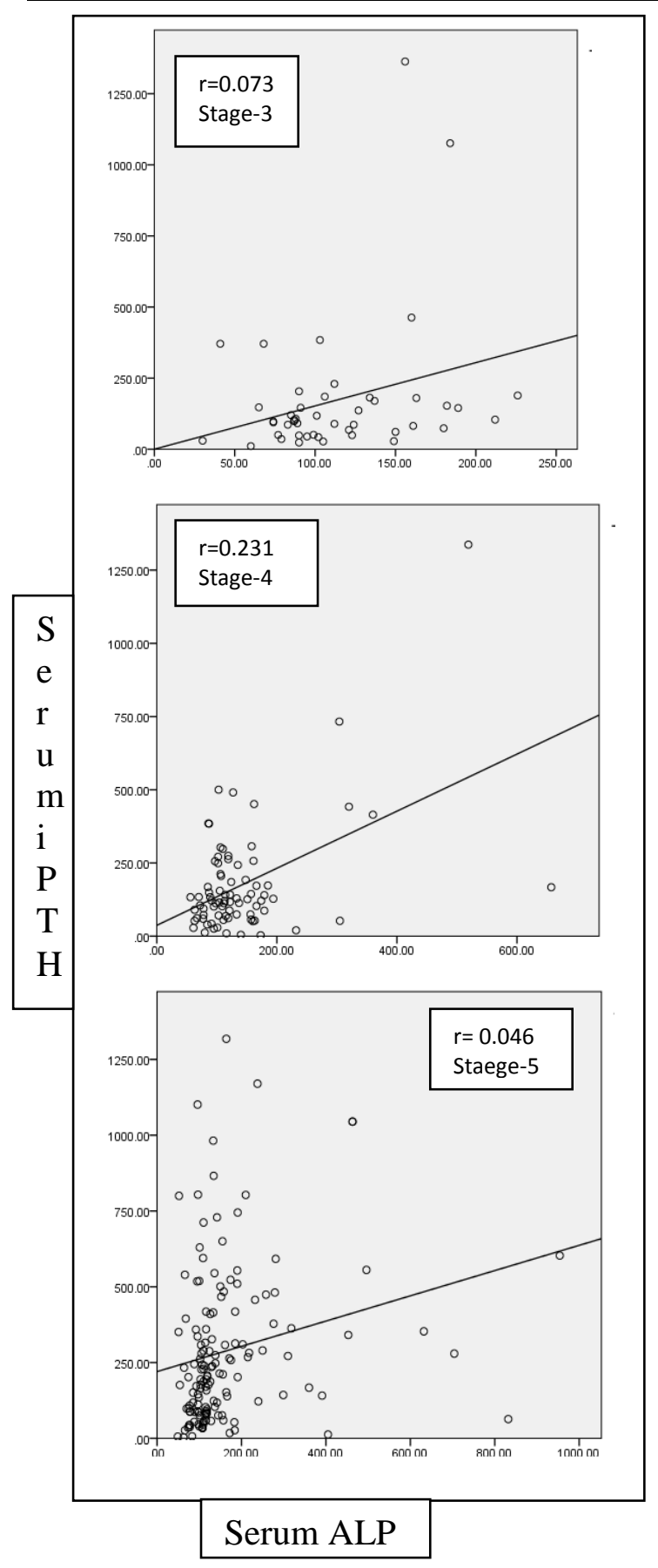

Fig.1: Correlation between serum iPTH and ALP in stage 3, 4 and 5 diabetic CKD-MBD patients

Table- 3 shows the rate of raised or elevated serum iPTH and ALP levels in stage 3, 4 and 5 CKDMBD cases. The serum iPTH level was raised in $79.6 \%, 83.3 \%$ and $72.5 \%$ CKD-MBD stage 3,4 and 5 cases respectively. But in comparison, the serum ALP was raised in significantly $(\mathrm{p}<0.01)$ low number of cases. It was $44.8 \%, 54.4 \%$ and $56.2 \%$ in CKD-MBD stage 3, 4 and 5 cases respectively. Overall the serum ALP was raised in only $53.9 \%$ CKD-MBD cases while iPTH was raised in $76.8 \%$ cases. There was no significant increase of rate of positivity of serum $\mathrm{iPTH}$ and ALP in any stage of CKD-MBD cases ( $p>0.05)$.

Figure-1 shows the correlation analysis between serum $\mathrm{PPTH}$ and ALP of CKD-MBD stage 3, 4 and 5 cases $(r=0.073, r=0.231$ and $r=0.046$ for stage 3,4 and 5 respectively).

\section{Discussion}

CKD-MBD is a recognized complication of advanced CKD patients but it is less addressed in our day to day practice. CKD-MBD has two distinct components; high iPTH related to high bone turn over and low iPTH resulting in adynamic bone disease [13]. Treatment of CKD-MBD is an integral component of CKD management. Serum iPTH is the key target for management of CKD-MBD $[14,15]$. Kidney disease wasting (KDW) also known as the malnutrition-inflammation complex, renal anemia and kidney bone disease (KBD) appear to be the 3 most important non-traditional risk factors associated with cardiovascular disease in CKD $[11,17]$. Kovesdy et al. described significant associations between higher total (nonspecific) ALP and increased all-cause mortality [18]. Unfortunately, there are very limited studies on this issue especially in this part of the world.

In our study, we observed significantly low rate (44.8\%-56.2\%) of raised serum ALP in our CKDMBD cases compared to $72.5 \%-83.2 \%$ rate of raised $\mathrm{iPTH}$ in those cases. Also, we did not observe the increase in the rate of raised serum iPTH and ALP with worsened CKD stages. In correlation analysis between $\mathrm{PTTH}$ and ALP, the $\mathrm{r}$ value was 0.046 to 0.231 for stage 3-5 cases indicating lack of useful association of the two markers. However, some studies have reported that elevated level of iPTH correlate well with elevated ALP level $[19,20]$.

The study had few limitations. This study included a small sample size in a single centre and we could not prospectively follow the patients over time and 
assess the different subtypes of ALP. However, since there was raised serum ALP in about half of our study cases, serum ALP could be used as a surrogate marker for iPTH to detect CKD-MBD case in resource constraint settings. Test for serum ALP could be a much cheaper and easily available than that of iPTH test.

\section{Authors' contributions}

MAA and WMMH had equal contributions in this study. MAA and WMMH were involved in designing the study, collection and analysis of data, literature review and writing of the manuscript. MAR, TAC, TS, MMB and SI critically reviewed the manuscript and had significant intellectual contribution.

\section{Competing interest}

Authors declare no conflict of interest.

\section{Funding}

None

\section{References}

1. Hill NR, Fatoba ST, Oke JL, Hirst JA, O'Callaghan CA, Lasserson DS, et al. Global Prevalence of Chronic Kidney Disease - A Systematic Review and Meta-Analysis. PLoS ONE. 2016; 11(7): e0158765.

2. Barsoum RS. Chronic kidney disease in the developing world. $N$ Engl J Med. 2006; 354: 997-9.

3. Freethi R, Raj AV, Pooniraivan K, Khan MR, Sundhararajan A, Venkatesan. Study of serum levels of calcium, phosphorus and alkaline phosphatase in chronic kidney. Int J Med Res Health Sci. 2016; 5(3): 49-56.

4. Nickolas TL, McMahon DJ, Shane E. Relationship between moderate to severe kidney disease and hip fracture in the United States. J Am Soc Nephrol. 2006; 17: 3223-32.

5. Tentori F, McCullough $\mathrm{K}$, Kilpatrick RD, Bradbury BD, Robinson BM, Kerr PG, et al. High rates of death and hospitalization follow bone fracture among hemodialysis patients. Kidney Int. 2014; 85: 166-73.

6. Nitsch D, Mylne A, Roderick PJ, Smeeth L, Hubbard R, Fletcher A. Chronic kidney disease and hip fracture related mortality in older people in the UK. Nephrol Dial Transplant. 2009; 24: 1539-44.

7. Mittalhenkle A, Gillen DL, Stehman-Breen CO. Increased risk of mortality associatedwith hip fracture in the dialysis population. Am J Kidney Dis. 2004; 44: 672-79.

8. Nosjean O, Koyama I, Goseki M, Komoda T. Tissue nonspecific alkaline phosphatases: Sugar moiety induced enzymic and antigenic modulations and genetic aspects. Biochem J.1997; 321: 297-303.

9. Sardiwa S, Magnusson P, Goldsmith DJ, Lamb EJ. Bone alkaline phosphatase in CKD-mineral bone disorder. Am J Kidney Dis. 2013; 62: 810-22.

10. Gardham C, Stevens PE, Delaney MP, Le Roux M, Coleman A, Lamb EJ. Variability of parathyroid hormone and other markers of bone mineral metabolism in patients receiving hemodialysis. Clin J Am Soc Nephrol. 2010; 5: 1261-67.

11. Souberbielle JC, Boutten A, Carlier MC, Chevenne G, CoumarosG, Law Son Body G. Inter method variability in PTH measurement: implication for the care of CKD patients. Kidney Int. 2006; 70: 345-50.

12. Sigrist MK, Taal MW, Bungay $P$, Mcintyre CW. Progressive vascular calcification over 2 years is associated with arterial stiffening and increased mortality in patients with stages 4 and 5 chronic kidney disease. Clin J Am Soc Nephrol. 2007; 2: 1241-48.

13. Coen G. Adynamic bone disease: an update and overview. J Nephrol. 2005; 18: 117-22.

14. Moe S, Drüeke T, Cunningham J, Goodman W, Martin K, Olgaard K, et al. Definition, evaluation and classification of renal osteodystrophy: a position statement from Kidney Disease: Improving Global Outcomes (KDIGO). Kidney Int. 2006; 69(11): 1945-53. 
15. Kidney Disease: Improving Global Outcomes (KDIGO) CKD Work Group. KDIGO 2012 Clinical Practice Guideline for the Evaluation and Management of Chronic Kidney Disease. Kidney Int. 2013; 3(Suppl): 1-150.

16. Kalantar-Zadeh, Kuwae N, Regidor DL, Kovesdy CP, Kilpatrick RD, Shinaberger CS, et al. Survival predictability of time-varying indicators of bone disease in maintenance hemodialysis patients. Kidney Int. 2006; 70: $771-80$.

17. Lee GH, Benner D, Regidod DL, KalantarZadeh K. Impact of kidney bone disease and its management on survival of patients on dialysis. J Ren Nutr. 2007; 17(1): 38-44
18. Kovesdy CP, Ureche V, Lu JL, and Kamyar KJ. Outcome predibility of serum alakaline phosphatase in men with pre-dialysis CKD. Nephrol Dial Transplant. 2010; 25:3003-3011.

19. Young EW, Albert JM, Satayathum S, Goodkin DA, Pisoni RL, Akiba T, et al. Predictors and consequences of altered mineral metabolism: The Dialysis outcomes and practice patterns study. Kidney Int. 2004; 67: 1179-87.

20. Albalate $M$, de la Piedra $C$, Fernandez $C$, Lefort M, Santana H, Hernando $\mathrm{P}$, et al. Association between phosphate removal and markers of bone turnover in haemodialysis patients. Nephrol Dial Transplant. 2006; 21: 1626-32. 